\title{
A relação entre designers e jornalistas na produção de informações para as reportagens em redações jornalísticas
}

\author{
The relationship between designers and journalists in the production \\ of information to reports in newsrooms
}

Juliana Lotif Araújo, Eva Rolim Miranda, Gonçalo André Moço Falcão

reportagem, design da informação, jornalismo, redação jornalística.

\begin{abstract}
Este artigo trata da relação entre jornalistas e designers em redações jornalísticas integradas e em redações nativas digitais no contexto da produção de reportagens multimídia e reportagens multiplataforma. Foram realizadas entrevistas com seis profissionais, três jornalistas e três designers, atuantes em redações na cidade de Fortaleza (Ceará-Brasil) sobre suas rotinas de trabalho e práticas profissionais. Concluiu-se que ainda existe pouco espaço para o trabalho dos designers na construção do texto jornalístico nas redações e também que, diante do atual contexto de consumo de informações jornalísticas, faz-se cada vez mais necessário o trabalho colaborativo e multidisciplinar na construção de reportagens que explorem o potencial das mídias digitais e dos veículos tradicionais.
\end{abstract}

report, information design, journalism, newsroom.

This article deals with the relationship between journalists and designers in integrated journalistic newsrooms and in native digital newsrooms in the context of the production of multimedia reports and multiplatform reports. Interviews were carried out with six professionals, three journalists and three designers, working in newsrooms in the city of Fortaleza (Ceará-Brazil) about their work routines and professional practices. It was concluded that there is still little space for the work of designers in the construction of the journalistic text in the newsrooms and also, given the current context of consumption of journalistic information, collaborative and multidisciplinary work in the construction of reports that explore the potential of digital media and traditional media.

\section{Jornalismo e Design da Informação em contexto}

O Jornalismo e o Design da Informação têm em comum a configuração de informações e a transmissão de conteúdos com o foco no público como orientadores de suas práticas profissionais, tanto nas redações jornalísticas como nos escritórios de design. A prática do Design assenta-se sobre um grupo de processos e ainda sobre uma forma de pensamento focada no usuário o que possibilita a melhoria do processo jornalístico. Tal melhoria pode se dar através de uma compreensão diferente do seu papel na vida real de quem o consome e de um trabalho direto com as comunidades nas quais as organizações jornalísticas estão inseridas de forma a gerar coberturas e contar histórias relevantes para o público. O texto jornalístico,

Anais do $10^{\circ} \mathrm{CIDI}$ e $10^{\circ} \mathrm{CONGIC}$

Kelli C.A.S. Smythe, Rafael de Castro Andrade (orgs.)

Sociedade Brasileira de Design da Informação - SBDI

Curitiba | Brasil | 2021
Proceedings of the $10^{\text {th }} \mathrm{CIDI}$ and $10^{\text {th }} \mathrm{CONGIC}$

Kelli C.A.S. Smythe, Rafael de Castro Andrade (orgs.)

Sociedade Brasileira de Design da Informação - SBDI Curitiba | Brazil | 2021 
seja ele verbal, com seus aspectos visuais, pictórico ou esquemático, deve ser planejado e executado com o horizonte da compreensão das informações por parte dos leitores.

O jornalismo sempre mudou suas práticas de acordo com a evolução das tecnologias comunicacionais. Desde a expansão da rede de transporte, no século XIX, passando pelo uso do telégrafo e do telefone, até a informatização das redações no final dos anos de 1980. Já a partir dos anos 2000, com o uso da internet para fins comerciais, surgiu o jornalismo em rede. Estas mudanças afetam a profissão como um todo quando trazem um equilíbrio de poder entre fornecedores e usuários de informação (Bardoel \& Deuze, 2001) além de uma enorme dispersão de fontes informativas, gerando confusão sobre a credibilidade da profissão.

$\mathrm{Na}$ atual fase do jornalismo, denominada de Jornalismo Pós-Industrial, "o que está em xeque não é a atividade jornalística, mas um determinado modelo de negócios sobre o qual a profissão se estabeleceu historicamente" (Satuf, 2016). Anderson et al. (2014) afirmam que as novas possibilidades do jornalismo, com a explosão de ferramentas e técnicas de comunicação iniciadas nos anos 2000, também exigem novas formas de organização. Os autores destacam ainda que, o atual ecossistema midiático obriga as empresas jornalísticas a mudarem não só de tática, mas também de autoconceito. Segundo Chaplin (2016), no presente é raro encontrar referências acerca do futuro do jornalismo que não façam menção ao pensamento, às práticas ou à visão dos usuários, próprias dos projetos de design.

A realidade das redações jornalísticas de hoje em dia é pautada pela integração e pela convergência midiática, que altera também as rotinas produtivas e implementa novos processos ao fazer jornalístico (Lordêlo, 2015). Neste contexto, as práticas adotadas pelas corporações de mídia causam desconfiança entre os profissionais e os pesquisadores da área. Questiona-se se os modelos de rotina produtiva adotados são motivados pela redução de custos operacionais, diante da acentuada queda de público dos veículos tradicionais (impresso, rádio e televisão), ou se a motivação é oriunda da realidade multiplataforma e da necessidade de renovação das práticas.

Já do ponto de vista dos jornalistas, tem-se que o conteúdo produzido pela maioria deles é multilinguagem e a publicação é multiplataforma, ou seja, a mesma equipe de profissionais gera informações que contém texto verbal, vídeos, imagens fotográficas e esquemas gráficos que serão veiculados em mídia impressa, audiovisual, digital e radiofônica tornando cada vez mais raras as especializações e as divisões de trabalho por mídia.

É neste cenário de mudanças de conceitos e de práticas profissionais que a produção de reportagens jornalísticas se insere atualmente. No campo de discussão sobre gêneros jornalísticos, a reportagem pode ser definida como "o relato ampliado de um acontecimento que já repercutiu no organismo social e produziu alterações que são percebidas pela instituição jornalística" (Marques de Melo, 2009, p. 65).

A reportagem traz um aprofundamento maior da realidade, possui "além do texto principal, infográficos, imagens, box e cronologia dos fatos” (Oliveira \& Seixas, 2011 p.03) e também são trazidos à tona os saberes prévios em relação ao tempo e ao espaço dos acontecimentos, fazendo conexão entre fatos, explicando uma situação. 
A reportagem é, portanto, um terreno fértil para a aplicação dos diversos saberes e para a atuação dos variados profissionais que trabalham na criação, produção e veiculação da informação jornalística. Neste artigo, será abordada a relação entre jornalistas e designers da informação no contexto das reportagens; para tanto, foi feito um apanhado teórico sobre o campo do Design da Informação na sua relação com o Jornalismo.

O Design da Informação, entendido aqui como uma área do Design Gráfico, reconhece "a importância da forma como um modo de estruturar a realidade e a figura do designer como um ator político" (Souza et al., 2016). Segundo Pettersson (2014), o design da informação existe para satisfazer as necessidades dos destinatários compreendendo análise, planejamento, apresentação e compreensão das mensagens.

No que tange ao Jornalismo, o design tem a função de "mediar a informação jornalística planejando coberturas e edições, organizando as informações, desenvolvendo formas alternativas de narrar os fatos, explicando-os de forma clara" (Moraes, 2013, p. 25).

Para Charaudeau (2013), os elementos visuais apresentados nos materiais jornalísticos têm a função de provocar efeitos de verdade quando tendem a provar a autenticidade ou a verossimilhança dos fatos atribuindo valor às informações dadas. $O$ autor afirma ainda que a reconstituição do acontecido pode funcionar como um testemunho ou um "procedimento de elucidação", em concordância com Sodré (2009), que afirma que a informação jornalística está na ordem da comprovação objetiva ou realista.

Nas redações jornalísticas, a reportagem sempre foi um espaço de integração entre jornalismo e design. Segundo Santos (2020), na reportagem é possível exercitar a criatividade e desenvolver conteúdos de interesse público com visualidade privilegiada na mídia. A reportagem conta com uma rotina diferenciada, com maior tempo de execução e com uma atenção especial à fotografia e aos aspectos do design.

$\mathrm{Na}$ organização das redações é comum encontrar setores de arte, editorias de arte, editorias de imagem e até editorias de infografia em quase todos os veículos de comunicação, independente do suporte de veiculação. Nesses setores geralmente trabalham os designers ou os jornalistas que têm formação também em design (o que é mais raro) e são executadas as "artes", ou seja, o planejamento e a produção visual/editorial da publicação ou das publicações. Esses setores, em sua maioria, atendem a todas as chamadas editorias de conteúdo (cidades, nacional, internacional, cultura e esportes, por exemplo) e produzem material para todos os veículos e todas as plataformas que a corporação de mídia dispõe. Em alguns casos, existem setores específicos para os conteúdos veiculados em mídia digital onde atuam jornalistas, designers e também programadores.

Atualmente, a maioria das redações jornalísticas podem ser classificadas em dois tipos: redações integradas $(\mathrm{RI})$, geralmente pertencentes à corporações de mídia que reúnem vários veículos de comunicação em diversas mídias e produzem conteúdos para multiplataforma e as Redações Nativas Digitais (RND), que geralmente abarcam veículos com produção apenas para mídias digitais. 
Na rotina de trabalho das $\mathrm{RI}$, geralmente o jornalista, seja ele repórter ou editor, articula com os veículos da corporação de mídia e com a equipe os espaços (em páginas, em minutos ou em destaque no portal) e os demais profissionais que irão atuar em derminada reportagem. São chamados ao trabalho com tal reportagem fotógrafos, designers, câmeras, editores de vídeo ou editores de áudio, mas raramente estes profissionais se dedicam exclusivamente à produção deste conteúdo, tendo que conciliar o trabalho da reportagem com os demais afazeres do cotidiano da redação. Também persiste o formato da dupla jornalista e fotojornalista na apuração em campo para as reportagens.

Já a rotina das RND, que têm estrutura física mais modesta em comparação com as RI, foi criada para veículos que têm atuação exclusiva no meio digital sem integração com nenhuma outra empresa de legado de mídia. Segundo Gonçalves (2018), as RND possuem uma equipe reduzida de profissionais e um fluxo de trabalho mais horizontalizado. Neste tipo de redação os repórteres ficam mais livres para definir sua rotina de trabalho e o processo de edição é feito de forma mais colaborativa com os editores definindo o destaque que cada conteúdo terá na página principal da publicação.

Percebe-se que a relação entre jornalistas e designers ainda se mantém baseada em uma lógica industrial que divide os fazeres desses dois profissionais, ficando o segundo com a tarefa de dar forma e ilustrar o trabalho do primeiro. Os jornalistas não costumam se preocupar com a organização visual das matérias criando apenas o texto verbal, passando para os diretores de arte ou diagramadores (os designers) a tarefa de dar forma a um conteúdo.

Na reportagem, o designer não costuma influenciar no conteúdo textual e até sua atuação na visualidade tem limitações impostas pelo projeto gráfico da publicação e pela coordenação dos repórteres e editores que têm o papel de "selecionar, hierarquizar e decidir o estilo estético para apresentar o conteúdo" (Santos, 2020). A autora complementa ainda que o designer discute e executa o plano desenvolvido pelos jornalistas, o que restringe sua autonomia profissional.

A respeito da visão que os profissionais têm uns dos outros no contexto das redações ainda é possível encontrar estudos da área do jornalismo que denominam designers e programadores, presentes nas redações de veículos digitais, como tecnoatores, classificandoos como profissionais que dominam a tecnologia e distinguindo-os dos jornalistas. Os tecnoatores "conquistam proeminência diante da carência ou completa falta de expertise dos jornalistas em um momento de acelerada mudança nas tecnologias" (Canavilhas et al., 2016 p.2). Os mesmos estudos apontam que tanto jornalistas quanto designers têm dificuldade de compreender o trabalho um do outro na construção do conteúdo jornalístico.

Porém, os estudos de Santos (2020) comprovam que as práticas convergentes estão gerando mais interação e interdisciplinaridade nas redações. Acredita-se que através do conhecimento sobre as possibilidades de atuação, as fronteiras profissionais e o trabalho em colaboração, esta visão que os profissionais têm uns dos outros e consequentemente os resultados dos trabalhos feitos por eles possam mudar. 
O relatório da Columbia Journalism Review ${ }^{1}$ sobre a relação entre o Jornalismo e o Design (Chaplin, 2016) identifica quatro aplicações primárias do design em contextos jornalísticos:

- Testagem de soluções preliminares: o teste de soluções antes de implementá-las faz com que se identifique de forma rápida os caminhos mais promissores a seguir sem que se faça grandes investimentos nas organizações;

- Uso de ferramentas de escuta da audiência: estas servem como reforço da compreensão que a organização tem do público diante dos seus produtos;

- Entendimento do sistema: ao reconceitualizar as instâncias do jornalismo, entendendo-o como pertencente a um ecossistema midiático mais amplo, faz-se com que as notícias, reportagens e outros formatos jornalísticos cheguem aos seus usuários com uma maior variedade de estratégias de narrativa e em diversas plataformas;

- Promoção do jornalismo cidadão: através do aproveitamento das experiências dos leitores com foco na exploração não só dos problemas da comunidade, mas também das maneiras de abordá-los.

Este trabalho foca-se claramente na terceira aplicação primária, sem recusar abordar a quarta aplicação. Para que estes processos decorram, o mesmo documento oferece sugestões detalhadas para a sua implementação, identificando oito processos (Chaplin, 2016):

- Pensamento em sistema: entender que as notícias e as instituições jornalísticas são parte de um ecossistema midiático que é informacional, social e organizacional;

- Centralização das inovações nas pessoas e não na tecnologia: criar produtos para as pessoas ao mesmo tempo que surgem novas tecnologias que possibilitam inovações;

- Identificação do verdadeiro problema: analisar cada situação e não partir do pressuposto que já se sabe qual é o problema;

- Escuta ativa e outras ferramentas para conhecer melhor seus usuários: utilizar recursos diversos de escuta e conhecimento do público para garantir melhor eficácia da informação;

- Pensamento aberto: utilizar ferramentas democráticas e transparentes para geração de novas ideias como o brainstorm, por exemplo;

- Sintetização e classificação das ideias: identificar e distinguir quais ideias devem ser levadas a diante assim como fazer fusão de ideias para geração de novas;

- Prototipagem e iteração ou aprender enquanto faz: realizar versões preliminares e de teste para entender como é a recepção do público em vez de apenas planejar;

\footnotetext{
${ }^{1}$ A missão da Columbia Journalism Review assemelha-se, de alguma modo, àquilo que procuramos com este trabalho. Apesar de usar uma perspectiva diferente, a CJR procura fornecer contexto teórico de ponta para o mundo do jornalismo em rápida transformação. A Columbia Journalism Review é uma das vozes mais respeitadas na análise e crítica aos processos jornalísticos, produzindo relatórios que permitem um aprofundamento do conhecimento da indústria.
} 
- Testagem: observar os usuários enquanto interagem com os produtos (faz parte do item anterior com a ideia de iteração).

\section{Jornalistas e designers no trabalho com a reportagem}

A ligação entre o Jornalismo e o Design não é uma novidade absoluta. Contudo, este trabalho o fará através de uma perspectiva específica. O relatório feito pela Columbia Journalism Review (Chaplin, 2016), em que se tenta conectar o jornalismo e o design para além do design editorial ou do "design thinking" passando a aplicar a forma de fazer do design na resolução de problemas complexos como os que o jornalismo enfrenta atualmente. O relatório foi feito com base em entrevistas com designers e jornalistas e quatro estudos de design em contexto - no BuzzFeed, The New York Times, National Public Radio e AL.com.

O estudo apresentado neste artigo, faz parte de uma pesquisa de doutorado que tem como objetivo principal gerar alternativas para o desenvolvimento de reportagens jornalísticas baseando-se nos métodos de projeto de Design da Informação, nas rotinas produtivas do jornalismo e no trabalho colaborativo entre designers e jornalistas.

Com o intuito de conhecer mais a fundo as características do trabalho dos jornalistas e designers na produção das reportagens no contexto brasileiro, foram feitas entrevistas com jornalistas e designers da cidade de Fortaleza (Ceará - Brasil).

A amostragem das entrevistas, feita por conveniência, foi composta por seis profissionais: um jornalista e uma designer de RI (grupo 1), uma jornalista e um designer que atuam como freelancers para veículos de corporações de mídia em projetos especiais (grupo 2) e um jornalista e uma designer de uma RND (grupo 3).

Devido ao contexto da pandemia da Covid-19, as entrevistas foram feitas através de recursos online como: chamada de vídeo pelos aplicativos Zoom e Meet, áudio no aplicativo WhatsApp e em texto escrito enviado por e-mail de acordo com a disponibilidade de cada participante. As chamadas de vídeo foram gravadas e tanto estas como os áudios do WhatsApp foram transcritos para análise.

A entrevista, do tipo estruturada e com perguntas abertas, foi construída com base nos estudos feitos para a fundamentação teórica deste artigo e também nas pesquisas de Fígaro (2018) e se dividiu em quatro blocos: identificação, local de trabalho, fluxo de trabalho e relação entre jornalistas e designers na construção de reportagens.

A partir das falas dos jornalistas e designers é possível tecer algumas considerações sobre a forma de trabalho, as visões dos profissionais sobre o trabalho um do outro e suas impressões sobre a construção de conteúdos jornalísticos.

Os profissionais têm entre 30 e 44 anos e atuam no mercado do jornalismo há mais de 10 anos. Tendo passado por outras redações, assessoria de comunicação e escritórios de design no estado do Ceará e em outras partes do Brasil.

Tanto jornalistas quanto designers revelam que produzem conteúdo para mais de uma mídia, ou seja, vivem realidades de trabalho multilinguagem e multiplataforma. Assim, 
geralmente os conteúdos produzidos por estes profissionais são veiculados em mídia impressa, audiovisual, digital e até radiofônica. Essa polivalência profissional é típica do jornalismo convergente praticado na atual fase pós-industrial e também faz parte das práticas do design contemporâneo.

A respeito do fluxo de trabalho, os jornalistas atuam a maior parte do tempo sozinhos e são responsáveis por gerenciar todo o processo de construção da reportagem acionando os outros profissionais (fotógrafos, designers, editores ou programadores) de acordo com cada fase do andamento do trabalho. Percebe-se também que a dupla repórter e fotógrafo ainda é predominante na apuração da reportagem.

"Eu sempre gosto de compartilhar esses materiais. É como se fosse o repórter sozinho, mas eu crio essa rede. Eu estabeleço uma rede para cada diferente pauta. Ela vai para um assunto e vai para uma editoria. Tudo depende do assunto. Eu vou chamando as pessoas e vou fazendo essas várias entregas. E na próxima reportagem podem ser outras pessoas com quem eu falo." (Jornalista grupo 1, 2020).

"Normalmente é fotógrafo, no mínimo fotógrafo, mas normalmente envolve cinegrafistas também. Na pré-produção pode ter um outro jornalista. Um jornalista de apoio. E na pós-produção aí vão entrar os editores. E aí na edição envolve um editor-chefe que vai dar o tom do material e aí para ele dar esse tom ele já conversou comigo antes que eu escrevesse. Entram também os profissionais de acabamento, digamos assim, quem vai dar o tom visual. O designer, por exemplo entra nesse momento." (Jornalista grupo 2, 2020).

"A gente sempre apresentava para elas (as publicitárias) os textos antes para terem uma noção de qual era a minha pegada da reportagem, se era uma coisa mais emotiva ou se a gente ia pegar mais um dado oficial." (Jornalista grupo 3, 2020).

Ainda sobre o fluxo de trabalho, no caso das reportagens feitas em RIs, é possível perceber uma atuação separada e às vezes distante entre jornalistas e designers. $\mathrm{O}$ ambiente da redação é integrado no sentido de produzir para integração das mídias, mas não necessariamente com integração de profissionais.

No caso dos freelancers, jornalistas e designers não se encontram ou sequer conversam. Os textos são repassados ao designer para diagramação e a relação se estabelece via meios digitais. Geralmente são os editores que definem o conteúdo visual com os designers e repassam as informações aos repórteres. Percebe-se nas respostas que os designers contribuem na finalização do processo dando a roupagem final que o material terá.

Já no fluxo relatado pelos profissionais da RND apresenta-se mais a perspectiva do trabalho em conjunto desde o início da produção da reportagem. Entretanto, nos três casos, é possível perceber que os designers atuam muito mais com a adequação da reportagem à identidade visual ou ao projeto gráfico do veículo do que com o design da informação na reportagem.

Como complemento, os profissionais do grupo 1 relataram que as soluções gráficas ou informativas poderiam ser melhoradas se os designers tivessem dedicação exclusiva para as reportagens. Atualmente os designers se dividem no trabalho entre o factual e o chamado especial. 
"Se for o fluxo de uma reportagem a gente vai ter mais cuidado. Porque depois da integração a gente acabou tendo que repensar. Antes quando eu estava só nas reportagens especiais, eu era só de reportagens especiais para o Diário do Nordeste. Isso era mais fácil. Hoje como produzo para todos, tudo isso precisa ser pensado e tem fluxos diferentes dependendo da plataforma e do veículo que isso vai." (Designer grupo 1, 2020).

O jornalista do grupo 1 relata que gostaria que o designer também fosse a campo como forma de presenciar os acontecimentos e daí extrair sua própria visão para o trabalho.

"No mundo ideal, no sonho, seria que em uma dessas viagens que eu fizesse eu pudesse levar o designer para ele ter esse contato que a gente acaba tendo, mas não temos a estrutura e nem profissional para fazer isso, mas seria o ideal. Eu já tive uma pauta que eu sugeri que eu não iria com o fotógrafo, eu iria com o designer. Porque eu acho que não vai ser a fotografia que vai resolver." (Jornalista grupo 1, 2020).

Nas perguntas sobre as contribuições de profissionais de outras áreas podem dar para o conteúdo das reportagens, tanto jornalistas quanto designers ressaltaram a visão de leitor ou usuário como um contributo relevante dessas pessoas "de fora".

Quando se pergunta sobre as contribuições do design para o conteúdo da reportagem, todos os entrevistados citaram a configuração visual como porta de acesso ao texto da reportagem como uma das principais contribuições. Nas respostas, percebe-se uma forte visão de conteúdo versus forma sendo o jornalista responsável pelo conteúdo e o designer responsável pela forma ou configuração visual do conteúdo. É possível perceber isso em falas do tipo "o primeiro contato é visual" (Jornalista grupo 1), "os profissionais de acabamento que vão dar o tom visual” (Jornalista grupo 2), "o jornalista produz o conteúdo propriamente dito" (Jornalista grupo 3), "essa estética passa a ser uma espécie de moldura do conteúdo" (Designer grupo 2).

Entretanto, a designer da RI e a designer da RND ressaltaram as contribuições que os recursos oriundos do design podem trazer para a narrativa e deixaram isso explícito em falas como "ele extrapola o que seria simplesmente a produção de um conteúdo ou a formatação de um conteúdo" (Designer grupo 1) e "vejo essas outras linguagens enriquecendo o produto jornalístico." (Designer grupo 3).

Sobre o uso dos recursos informativos oriundos do design nas reportagens, apenas o jornalista do grupo 3 respondeu que se sente satisfeito. Todos os outros profissionais entrevistados se dizem insatisfeitos e atribuem sua insatisfação à questões relacionadas com a organização do trabalho, seja pela quantidade de profissionais presentes na equipe, seja pela falta de contato entre jornalistas e designers, atribuída à pouca dedicação dos designers aos projetos de reportagem.

A respeito da relação entre os profissionais, são apresentadas visões diferentes em duas das três relações de trabalho abordadas na entrevista. Enquanto o jornalista da RI cita que é uma relação baseada no diálogo, a designer considera uma relação distante. No caso dos freelancers, a jornalista diz não ter contato com o designer enquanto o designer afirma que a 
relação se dá com diálogo entre os editores, mas com os repórteres ele geralmente só recebe o texto através de plataforma online. Já na RND percebe-se uma relação mais horizontal e tanto jornalista quanto designer afirmam que a relação é baseada no diálogo e na interação.

As falas da designer do grupo 1 estão em consonância com os estudos de Canavilhas et al. (2014), quando se trata da carência de expertise dos jornalistas em múltiplas linguagens e em formatos de mídia no atual cenário de mudanças da produção e da circulação de informações jornalísticas. A respeito dos seus colegas jornalistas, a designer afirma que:

"Tem carência de profissionais multiplataforma. Pode parecer um pouco polêmico, mas não é você fazer tudo, mas é você entender de tudo e ser capaz de compreender os usos, as características de cada plataforma, de cada suporte para que você consiga entender e propor conteúdo para cada plataforma de forma correta. Propor que aquele conteúdo seja trabalhado da forma correta em cada lugar. Eu falo só dessa carência de profissionais é como um todo isso também é uma carência no jornalista porque eu acho que há uma defasagem na forma como se faz jornalismo porque jornalismo não se faz sem interdisciplinaridade" (Designer grupo 1, 2020).

Já uma jornalista freelancer que trabalha para uma RI e um jornalista da RND fizeram afirmações a respeito das suas identidades profissionais e sobre o que pensam do trabalho dos designers que são importantes de destacar nesse cenário convergente e multiplataforma.

"Então o designer entra na edição do material dando leveza para aquele blocão de texto. Naqueles respiros então ele deixa leve uma coisa que poderia ser um textão. Visualmente é muito importante. Eu gosto de coisas que tem um respiros [sic]." (Jornalista grupo 2, 2020).

"Eu sou profissional das palavras que acredita muito que só o meu trabalho ele não tem impacto. A gente sempre trabalhou os materiais especiais (reportagens) na perspectiva de os produtos visuais serem pontos de leitura importantes e que complemente o que o texto está dizendo que seja uma continuidade do assunto ou que apresente uma outra perspectiva para o leitor."

(Jornalista grupo 3, 2020).

Percebe-se que o fluxo de trabalho, os profissionais envolvidos e a própria visão que a jornalista tem sobre o design ainda são muito pautadas pela lógica do jornalismo industrial, que traz o jornalista como figura central na construção da informação e trata outros profissionais, fotógrafos, designers e editores, como espécies de prestadores de serviço do jornalista. No caso do design e do designer, esta visão reduz o campo e o trabalho a uma questão ferramental, voltada para questões cosméticas ou para o design editorial apenas, estando estes profissionais, de maneira geral, presentes apenas no início e no fim do processo de construção da reportagem sem ida a campo ou apuração direta.

\section{Considerações finais}

John Seely Brown, antigo diretor científico da Xerox PARC e co-autor dos dois volumes de "Design Unbound" (Pendleton-Jullian \& Brown, 2018a, 2018b) afirmou: "mudamos para uma 
era em constante mutação" ${ }^{2}$. Das poucas constâncias que temos na atualidade é precisamente a permanente inconstância e a enorme rapidez a que estas alterações ocorrem. É uma marca sentida particularmente na indústria atual do jornalismo. Mesmo a elite do jornalismo americano tem muita dificuldade em lidar com gestores públicos que os insultam, afastam, recusam ou que contrariam abertamente a ciência e dados que são comumente aceitos como verdadeiros.

O êxodo em massa dos meios de comunicação impressos para os digitais acelerou profundamente os modelos de negócios e de organização das notícias tradicionais e alterou o comportamento do consumidor de forma irreconhecível. A indústria demorou muito tempo a reagir - o que é natural porque não é fácil reconfigurar uma indústria no seu todo - e no momento em que começou a trabalhar seriamente o digital, este já tinha se fragmentado em um número enorme de plataformas e oportunidades.

Diante do referencial teórico e das entrevistas realizadas entende-se que algumas mudanças são necessárias na forma de construir as reportagens jornalísticas diante do cenário multimídia e multiplataforma no qual se encontra o jornalismo hoje, o que impacta diretamente no resultado dos conteúdos jornalísticos.

Acredita-se que estas mudanças passam por caminhos que envolvem alterações na rotina jornalística no que tange ao estreitamento das fronteiras profissionais entre os atores envolvidos no processo de construção da notícia, principalmente jornalistas e designers, através de um maior conhecimento sobre os campos de atuação e de um trabalho colaborativo.

\section{Referências}

Anderson, C. W., Bell, E., \& Shirky, C. (2014). Post-Industrial Journalism: adapting to the present. Tow Center for Digital Journalism. https://academiccommons.columbia.edu/doi/10.7916/D8N01JS7

Bardoel, J., \& Deuze, M. (2001). "Network journalism": converging competencies of old and new media professionals. Australian Journalism Review, 23(2), 91.

Canavilhas, J. (2014). Jornalismo transmedia: um desafio ao velho ecossistema midiático. In C. E. C Moncada, D. Renó, S. R. L. Moreno, V. Gosciola (Ed.), Periodismo transmedia: miradas múltiples (p. 232). Editorial Universidad del Rosario.

Canavilhas, J., Satuf, I., De Luna, D., Torres, V., Baccin, A., \& Marques, A. (2016). Jornalistas e tecnoatores: a negociação de culturas profissionais em redações on-line. Revista

FAMECOS: Mídia, Cultura e Tecnologia., 23(3).

Chaplin, H. (2016). Guide to journalism and design. Columbia Journalism Review.

Charaudeau, P. (2013). Discurso das Mídias (Issue 1). Contexto.

Lordêlo, T. (2015). Rotinas produtivas flexíveis: as tendências e perspectivas do telejornalismo em redes televisivas no contexto de convergência no Brasil. Universidade Federal de Pernambuco.

Marques de Melo, J. (2009). Jornalismo: compreensão e reinvenções. Vozes.

Moraes, A. (2013). Infografia: História e Projeto. Blucher.

Oliveira, L., \& Seixas, L. (2011). A reportagem enquanto gênero jornalístico. XXXXIV Congresso Brasileiro de Ciências Da Comunicação, 1-15.

${ }^{2}$ V.O. "We have transitioned into an era of constant transitioning." 
Pettersson, R. (2014). Information Design Theories. Journal of Visual Literacy, 33(1), 1-96. https://doi.org/10.1080/23796529.2014.11674713

Sánchez, J. F., \& López-Pan, F. (1998). Tipologías de géneros periodísticos en España. Hacia un nuevo paradigma. In Comunicación y Estudios Universitarios (Issue 8, pp. 15-35).

Santos, Y. M. (2020). Jornalismo visual nas narrativas da grande reportagem brasileira. Universidade Federal de Pernambuco.

Satuf, I. (2016). Aplicativos agregadores de informação jornalística para dispositivos móveis: uma exploração pela teoria do ator-rede. Universidade da Beira Interior.

Sodré, M. (2009). A narração do fato: notas para um teoria do acontecimento. Vozes.

Souza, E., Oliveira, G., Miranda, E. R., Coutinho, S. G., Filho, G. P., \& Waechter, N. (2017). A forma como conteúdo : O caso de Irma Boom. $8^{\circ}$ Informational Design International Conference, 162-171. 